\title{
Coexistence of Neurofibromatosis Type 1 and Male Breast Cancer
} \author{
MD'; Fatih Altintoprak, MD; Belma Kocer, $\mathrm{MD}^{4}$ \\ 'Sakarya University Teaching and Research Hospital Department of General Surgery/ Sakarya, Turkey \\ ${ }^{2}$ Bozuyuk State Hospital Department of General Surgery Bilecik, Turkey \\ ${ }^{3}$ Sakarya University School of Medicine Department of Pathology Sakarya, Turkey \\ ${ }^{4}$ Sakarya University School of Medicine Department of General Surgery/ Sakarya, Turkey
}

Baris Mantoglu, MD ${ }^{1 *}$; Burak Kamburoglu, MD¹; Ismail Zengin, MD²; Kayhan Ozdemir, MD"; Ebru Kayra, MD³; Emre Gonullu,

\begin{abstract}
Breast cancer is one of the rarest types of cancer in men. Its incidence increases with age, as in women. Neurofibromatosis type 1 is an autosomal dominant genetic disease that predisposes to many cancer types. Neurofibromatosis and breast cancer have been more frequently distinguished and better studied in women. Characteristically, estrogen, progesterone receptors, negative, and overexpression of human epidermal growth factor receptor 2 (HER2) are detected in patients with female neurofibromatosis breast cancers. In cases reported so far, estrogen and progesterone receptors have been evaluated as positive and HER2 negative in male patients. With the high possibility of breast cancer development in female patients with neurofibromatosis at an earlier age, prompt and careful evaluation is required in terms of both examination and radiological imaging. Unfortunately, there are no thorough recommendations for breast cancer follow-up in male patients with neurofibromatosis. Here, we present a breast cancer, which is an uncommon type of cancer in male neurofibromatosis.

Keywords: Breast cancer, Male, Neurofibromatosis type 1

Cite this article as: Mantoglu B, Kamburoglu B, Zengin I, Ozdemir K, Kayra E, Gonullu E, et al. Coexistence of neurofibromatosis type 1 and male breast cancer. Arch Iran Med. 2021;24(11):852-855. doi: 10.34172/aim.2021.126
\end{abstract}

Received: January 11, 2021, Accepted: April 28, 2021, ePublished: November 1, 2021

\section{Introduction}

Breast cancer is an infrequent malignancy in men. ${ }^{1,2}$ Breast cancer incidence increases with length of life in men as in women, and men tend to be 5-10 years older than women at diagnosis. ${ }^{3-5}$ Breast cancer incidence in men has been reported to have increased over the last 25 years. ${ }^{6}$

Genetic risk factors related to male breast cancer risk have been identified. ${ }^{7}$ BRCA2/1 mutations appear to be the main risk factors, and the National Comprehensive Cancer Network (NCCN) Clinical Practice Guidelines in Oncology define appropriate follow-up in this population. ${ }^{8}$

Neurofibromatosis type 1 (NF1), an autosomaldominant hereditary disease previously known as von Recklinghausen disease, is the most frequent type of the disease. NF1 incidence is about 1 in 2600-3000 individuals, and about half of the cases show familial inheritance. ${ }^{9}$ Discrete cutaneous neurofibromas are the most common lesions which consist of soft, fleshy, sessile, or pedunculated tumors. They move with the skin upon examination and are not tender. Some are located within the dermis and can be palpated as soft spots in the skin, often with an overlying violaceous discoloration. ${ }^{10}$

Pathogenic variants of the NF1 gene located at chromosome $17 \mathrm{q} 11.2$ are the onset of NF1. ${ }^{11}$ Neurofibromin, a protein product, is part of guanosine triphosphate hydrolase (GTPase) activating proteins that induce intrinsic GTPase activity. Pathological variants of the NF1 gene that cause decreased protein function or expression give rise to breast cancer as well as tumors associated with NF1. ${ }^{12}$

Although the association between NF1 and female breast cancer has been evaluated in many studies, a close relationship could not be established in male NF1 patients due to the rarity of cases, with only five cases of NF1 in male breast cancer patients published to date. ${ }^{13-16}$

\section{Case Report}

A 57-year-old man was admitted to our general surgery outpatient clinic with a palpable painless mass in the left breast for about 4 months. The patient had a previous diagnosis of NF1 and was being followed up because of suspicious lesions in the duodenum and suprarenal gland. The patient was also queried about familial history of malignancies, including prostate, ovarian, and breast, but there were no specific issues. The diagnosis of NF1 had been confirmed by genetic consultation 3 years before, and heterozygous p.Ser1468Gly mutation in exon 33 of the NF1 gene was defined as relevant for NF1. Physical examination revealed numerous, smooth, pediculated to sessile, non-sensitive, epidermal lumps of different sizes on the entire body related to NF1 (Figures 1 and 2). Unlike other lesions, an irregular, rigid, fixed mass approximately $3 \mathrm{~cm}$ in size was palpated in the retro-areolar region of the left breast. There was a palpable lymph node on axillary 
examination. Breast ultrasonography was performed, and revealed a breast imaging-reporting and data system 4 (BIRADS 4) mass in the left breast with a suspicious left axillary lymph node. Tru-Cut biopsy was obtained from the mass, and fine-needle aspiration biopsy was performed simultaneously from the suspicious axillary lymph node. No metastatic lesions were detected on contrast-enhanced thoracic and abdominal tomography. Biopsy results obtained from the mass and axillae indicated invasive ductal carcinoma and carcinoma metastasis, respectively. On immunohistochemical evaluation, the samples were estrogen receptor (ER)-positive, progesterone receptor (PR)-positive, and HER2-negative with a $\mathrm{Ki}$ 67 proliferative (labeling) index of $20 \%$ (Figures 3 and 4). After receiving approval form the tumor board, the patient underwent left modified radical mastectomy. The patient was discharged on postoperative day (PD) 1 without any complaints. The axillary drain was removed on PD 7. Histopathological examination revealed invasive ductal carcinoma, histological grade III (Nottingham

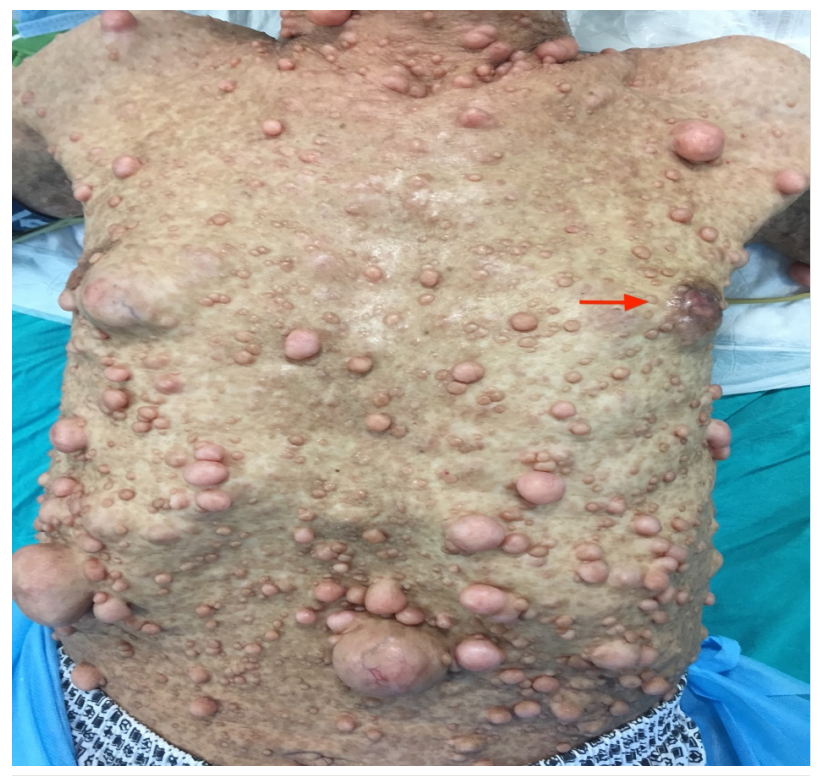

Figure 1. Multiple Sessile to Pedunculated Skin Nodules/ Right Breast Mass (Invasive Ductal Carcinoma) (Red arrow).

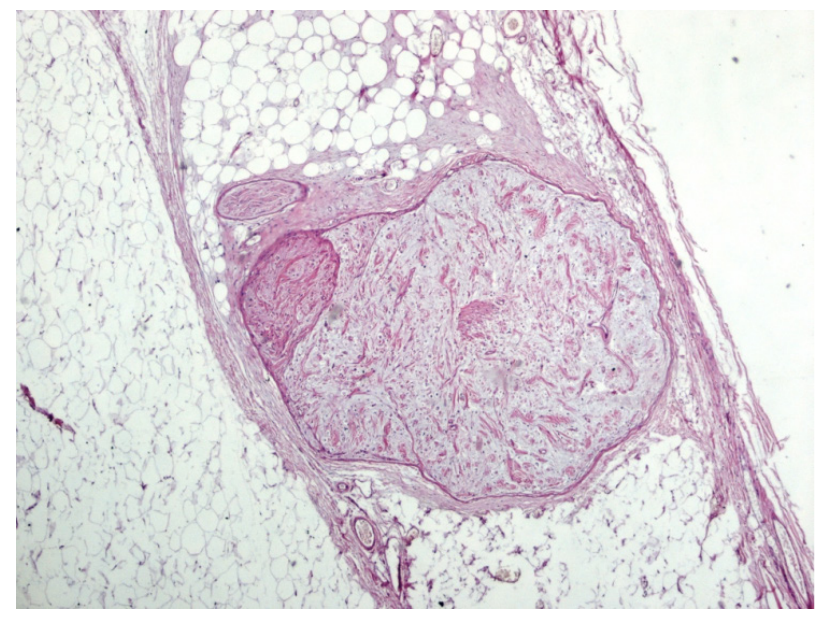

Figure 2. Well-Defined, Unencapsulated Areas of Neurofibroma. Note the myxoid formation of the stroma $(\times 40 \mathrm{H} \& \mathrm{E})$.
Score), lymphovascular invasion, without perineural invasion, with tumor-free overall surgical margins. The pathological stage was T2N2M0.

\section{Discussion}

Since the first published case of NF1 in $1933,{ }^{17} 16$ cohort studies, epidemiological studies, and many case reports and case series have described the correlation between NF1 and breast cancer in women. ${ }^{18}$ According to a recently published meta-analysis and systematic review, NF1 breast cancer patients under the age of 50 are five times more likely to have advanced breast cancer and may face increased mortality due to breast cancer. ${ }^{18}$ The NCCN guidelines also recommend early initiation of breast cancer screening in female patients with NF1 at the age of 30 , and a recent study provided evidence to support this recommendation. ${ }^{8}$ While the existence of the relationship between NF1 and the development of breast cancer in women has been established in a number of studies, due to the lower prevalence of male breast cancer and the low rate of association with diseases, such as NF1, the relation between NF1 and breast cancer in male patients has not been elucidated yet.

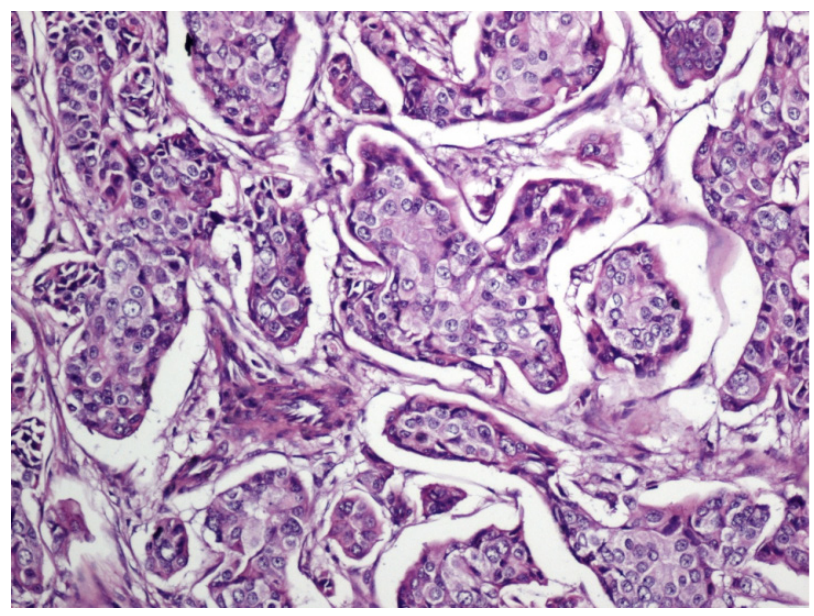

Figure 3. Atypical Invasive Ductal Carcinoma Areas within the Desmoplastic Stroma $(\times 100 \mathrm{H} \& \mathrm{E})$.

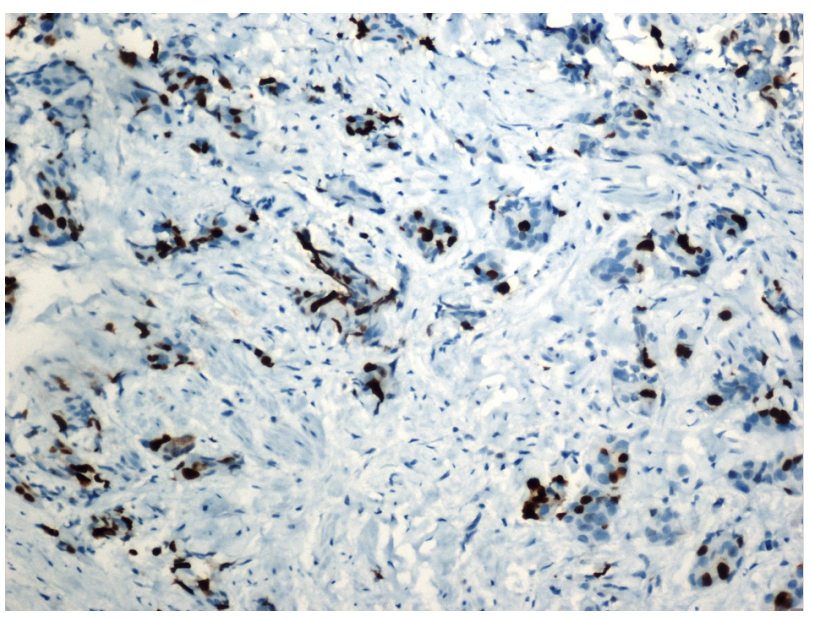

Figure 4. Luminal B invasive ductal carcinoma. 
Breast cancer in men accounts for $0.5-1 \%$ of all breast cancers defined in the USA and the UK, ${ }^{1,2}$ and less than $0.5 \%$ of all cancers in men in the USA. ${ }^{1}$ The annual prevalence of male breast cancer in Europe is 1 in 10000 men, and these cases account for less than $1 \%$ of the entire breast cancer patients. ${ }^{19}$ However, the rate is $>6 \%$ in Central African countries. ${ }^{20}$ The annual incidence of male breast cancer in Japan is below 5 in $1000000 .{ }^{21}$

Although the incidence of breast cancer is lower in males than females, it is necessary to be aware of the genetic risk factors related with male breast cancer. Individuals with BRCA2 mutation, a family background of breast cancer, a history of contralateral male breast cancer as well as Klinefelter syndrome (47XXY karyotype) are genetically at greater risk for male breast cancer. ${ }^{7}$ In addition, individuals with BRCA1, CHECK2, and PALB2 mutations and Cowden syndrome (germline PTEN mutations) are at low to moderate risk for male breast cancer. ${ }^{7}$ The current NCCN guidelines recommend that men who test positive for BRCA1/2 pathogenic or likely pathogenic variants should have annual clinical breast examinations and self-examinations beginning at 35 years of age. ${ }^{8}$ Mammographic screening in male breast cancer is not yet recommended due to limited data. ${ }^{8}$

Male breast cancer is typically detected at a more advanced stage than females at the time of admission due to both its rarity and the low level of awareness of individuals regarding this issue. ${ }^{22}$ Nearly $90 \%$ of breast cancers in men are invasive ductal carcinomas, hormone receptorpositive subtype, as in postmenopausal women. ${ }^{3,23}$ The case presented here was a hormone receptor-positive invasive ductal carcinoma.

As coexistence of NF1 and breast cancer is encountered more frequently in women than men, it has been better evaluated in women, and there is a body of literature in terms of both the correlation between NF1 and breast cancer and the follow-up of female patients with NF1. Imaging modalities are essential in patients with NF1 because of the low survival rate. ${ }^{24}$ Therefore, for timely identification of breast cancer, close follow-up with ultrasonography (USG) or magnetic resonance imaging will be more appropriate than mammography. This is mainly because many patients show multiple neurofibromas. ${ }^{25}$ Therefore, we performed breast USG instead of mammography to diagnose our patient.

Female breast cancer patients with NF1 are characteristically ER-negative and PR-negative, and have elevated HER2 consequences, low 5-year survival rate, and higher tumor grade. ${ }^{26}$ The coexistence of NF1 and breast cancer in women is related to a risk of breast cancer at a younger age compared to the general population. ${ }^{27}$ Therefore, there may be differences in breast cancers between female and male patients with NF1. Although cases of hormone receptor-positive male NF1 breast cancer have been reported, there are not enough data to determine whether NF1 can cause breast cancer in men at an earlier age.
Both alleles of NF1 need to be inactivated to influence carcinogenesis, but there is emerging evidence that haploinsufficiency or reduced expression may also have a functional impact. ${ }^{28}$

Interestingly, although the BRCA1 and NF1 genes are located on the same chromosome, there are no comprehensive data on the relationship between these two genes, and moreover, the BRCA2 gene is frequently associated with breast cancer in men. ${ }^{29}$ Heterozygous lack of the NF1 gene in women with neurofibromatosis is characteristic of breast cancer development. ${ }^{30}$ This genomic alteration may be efficient in male breast cancer, as in our case. However, further detailed genetic research is necessary to define the precise relationships of these diseases in men.

Similar to many other genes, it has been demonstrated in human cell cultures that tamoxifen resistance is related to the suppression of the NF1 gene. ${ }^{31}$ Therefore, tamoxifen, which plays an essential role in treatment of ER and PR positive breast cancer, may not show the desired effect during treatment of patients with NF1. However, this must be clarified by evidence-based studies in the future.

The low incidence of breast cancer in men and its association with an infrequent syndrome, such as NF1, may hinder both the diagnosis and follow-up of these patients. Although only a few cases have been reported to date, we conclude that male NF1 patients should be followed up carefully for breast cancer risk similar to women with NF1.

\section{Authors' Contribution}

BM, MBK: Design, data collection, data analysis, writing and revision. EG, İ, KO, EK: Data collection, data interpretation, and revision. BK: Data analysis, writing and final revision. FA: Study interpretation and revision. All authors read and approved the final manuscript.

\section{Conflict of Interest Disclosures}

The authors declare no conflicts of interest.

\section{Ethical Statement}

Ethical principles were followed for case presentation. Patient identification information was kept confidential.

\section{References}

1. Siegel RL, Miller KD, Jemal A. Cancer statistics, 2019. CA Cancer J Clin. 2019;69(1):7-34. doi: 10.3322/caac.21551.

2. White J, Kearins O, Dodwell D, Horgan K, Hanby AM, Speirs V. Male breast carcinoma: increased awareness needed. Breast Cancer Res. 2011;13(5):219. doi: 10.1186/bcr2930.

3. Giordano SH, Buzdar AU, Hortobagyi GN. Breast cancer in men. Ann Intern Med. 2002;137(8):678-87. doi: 10.7326/0003-4819-137-8-200210150-00013.

4. Nahleh ZA, Srikantiah R, Safa M, Jazieh AR, Muhleman A, Komrokji R. Male breast cancer in the veterans affairs population: a comparative analysis. Cancer. 2007;109(8):14717. doi: 10.1002/cncr.22589.

5. Anderson WF, Althuis MD, Brinton LA, Devesa SS. Is male breast cancer similar or different than female breast cancer? Breast Cancer Res Treat. 2004;83(1):77-86. doi: 10.1023/B:BR EA.0000010701.08825.2d.

6. Giordano SH, Buzdar AU, Hortobagyi GN. Breast cancer 
in men. Ann Intern Med. 2002;137(8):678-87. doi: 10.7326/0003-4819-137-8-200210150-00013.

7. Abdelwahab Yousef AJ. Male breast cancer: epidemiology and risk factors. Semin Oncol. 2017;44(4):267-72. doi: 10.1053/j. seminoncol.2017.11.002.

8. Daly MB, Pal T, Berry MP, Buys SS, Dickson P, Domchek SM, et al. Genetic/familial high-risk assessment: breast, ovarian, and pancreatic, version 2.2021, NCCN clinical practice guidelines in oncology. J Natl Compr Canc Netw. 2021;19(1):77-102. doi: 10.6004/jnccn.2021.0001.

9. Evans DG, Howard E, Giblin C, Clancy T, Spencer H, Huson $S M$, et al. Birth incidence and prevalence of tumor-prone syndromes: estimates from a UK family genetic register service. Am J Med Genet A. 2010;152A(2):327-32. doi: 10.1002/ajmg.a.33139.

10. Plotkin SR, Bredella MA, Cai W, Kassarjian A, Harris GJ, Esparza S, et al. Quantitative assessment of whole-body tumor burden in adult patients with neurofibromatosis. PLoS One. 2012;7(4):e35711. doi: 10.1371/journal.pone.0035711.

11. Gutmann DH, Ferner RE, Listernick RH, Korf BR, Wolters PL, Johnson KJ. Neurofibromatosis type 1. Nat Rev Dis Primers. 2017;3:17004. doi: 10.1038/nrdp.2017.4.

12. Messiaen LM, Wimmer K. NF1 mutational spectrum. Monogr Hum Genet. 2008;16:63-77. doi: 10.1159/000126545.

13. Mann N, Ma T, Dalton A. Neurofibromatosis type 1 and male breast cancer: emerging risk factor? J Surg Case Rep. 2017;2017(7):rjw138. doi: 10.1093/jscr/rjw138.

14. Ronchese F. Neurofibromatosis and adenocarcinoma of (male) breast. AMA Arch Derm Syphilol. 1953;68(3):359.

15. Lakshmaiah KC, Kumar AN, Purohit S, Viveka BK, Rajan KR, Zameer MAL, et al. Neurofibromatosis type I with breast cancer: not only for women! Hered Cancer Clin Pract. 2014;12(1):5. doi: 10.1186/1897-4287-12-5.

16. Tandon M, Panwar P, Garg P, Chintamani, Siraj F. Neurofibromatosis with male breast cancer--risk factor or COincidence? Report of two rare cases. Breast Dis. 2015;35(1):2932. doi: $10.3233 / \mathrm{bd}-140387$.

17. Jackson $\mathrm{AH}$. Three cases of multiple neurofibromatosis with malignant degeneration. J Nerv Ment Dis. 1933;78(6):581-96.

18. Suarez-Kelly LP, Yu L, Kline D, Schneider EB, Agnese DM, Carson WE. Increased breast cancer risk in women with neurofibromatosis type 1: a meta-analysis and systematic review of the literature. Hered Cancer Clin Pract. 2019;17:12. doi: 10.1186/s13053-019-0110-z.

19. Sasco AJ, Lowenfels $A B$, Pasker-de Jong P. Review article: epidemiology of male breast cancer. A meta-analysis of published case-control studies and discussion of selected aetiological factors. Int J Cancer. 1993;53(4):538-49. doi: 10.1002/ijc.2910530403.

20. Surveillance, Epidemiology, and End Results (SEER) Program. Public-Use Data (1993-1997). Bethesda, MD: National Cancer Institute, Division of Cancer Control and Population Sciences, Surveillance Research Program, Cancer Statistics Branch; 2000.

21. Cancer incidence in five continents. Volume IX. IARC Sci Publ. 2008(160):1-837.

22. Culell P, Solernou L, Tarazona J, Roma J, Martí E, Miguel A, et al. Male breast cancer: a multicentric study. Breast J. 2007;13(2):213-5. doi: 10.1111/j.1524-4741.2007.00412.x.

23. Chavez-Macgregor M, Clarke CA, Lichtensztajn D, Hortobagyi GN, Giordano SH. Male breast cancer according to tumor subtype and race: a population-based study. Cancer. 2013;119(9):1611-7. doi: 10.1002/cncr.27905.

24. Rasmussen SA, Yang Q, Friedman JM. Mortality in neurofibromatosis 1 : an analysis using U.S. death certificates. Am J Hum Genet. 2001;68(5):1110-8. doi: 10.1086/320121.

25. Da Silva AV, Rodrigues FR, Pureza M, Lopes VG, Cunha KS. Breast cancer and neurofibromatosis type 1: a diagnostic challenge in patients with a high number of neurofibromas. BMC Cancer. 2015;15:183. doi: 10.1186/s12885-015-1215-z.

26. Uusitalo E, Kallionpää RA, Kurki S, Rantanen M, Pitkäniemi $\mathrm{J}$, Kronqvist $\mathrm{P}$, et al. Breast cancer in neurofibromatosis type 1: overrepresentation of unfavourable prognostic factors. $\mathrm{Br} J$ Cancer. 2017;116(2):211-7. doi: 10.1038/bjc.2016.403.

27. Madanikia SA, Bergner A, Ye X, Blakeley JO. Increased risk of breast cancer in women with NF1. Am J Med Genet A. 2012;158A(12):3056-60. doi: 10.1002/ajmg.a.35550.

28. Berger AH, Knudson AG, Pandolfi PP. A continuum model for tumour suppression. Nature. 2011;476(7359):163-9. doi: 10.1038/nature10275.

29. Liede A, Karlan BY, Narod SA. Cancer risks for male carriers of germline mutations in BRCA1 or BRCA2: a review of the literature. J Clin Oncol. 2004;22(4):735-42. doi: 10.1200/ jco.2004.05.055.

30. Güran S, Safali M. A case of neurofibromatosis and breast cancer: loss of heterozygosity of NF1 in breast cancer. Cancer Genet Cytogenet. 2005;156(1):86-8. doi: 10.1016/j. cancergencyto.2004.04.019.

31. Mendes-Pereira AM, Sims D, Dexter T, Fenwick K, Assiotis I, Kozarewa I, et al. Genome-wide functional screen identifies a compendium of genes affecting sensitivity to tamoxifen. Proc Natl Acad Sci U S A. 2012;109(8):2730-5. doi: 10.1073/ pnas. 1018872108. 